\title{
EDITORIAL
}

\section{The Defence Medical Services - How Comprehensive?}

The long gestation period of each issue of the Journal of the Royal Army Medical Corps renders editorial consideration of contemporary issues generally impossible. This editorial must be written at least $2 \frac{1}{2}$ months before the date of publication. Inevitably therefore any comment on the profound political changes affecting Europe, their effects on the Army as a whole and the RAMC in particular is bound to be overtaken by events. That there will be changes is not in doubt and it is entirely correct that the overall shape and capability of the Defence Medical Services should come under scrutiny.

Clearly the Army, wherever it is based, needs primary care and this requires doctors with a similar training to that of civilian general practitioners. However, Army primary care doctors also need to be competent in advanced resuscitation and minor surgery, skills which many civilian GPs lack. In addition Army primary care demands a knowledge of occupational and preventive medicine. The Military role imposes a requirement for personnel fitness, both physical and mental, which is unknown in civilian practice. Although the medical professional training of such doctors continues to be based on civilian training programmes, further selection and military training will continue to absorb resources. It is doubtful whether these can be spread over the 3 Services as the working environment of Naval, Army and Air Force primary care doctors differs significantly. The future of military primary care thus seems assured, but what of the hospital specialities?

In peace and in war there is a demonstrable requirement for any Army to be supported by adequate surgical and anaesthetic services. The popular concept of modern military medicine is that of the MASH Unit. No doubt many lives are saved by skilled surgical intervention shortly after wounding, but is this the total hospital service required? Experience during the 2nd World War and in more recent conflicts has demonstrated the need for the so-called minor surgical specialities: plastic surgery, oro-maxillo-facial surgery, ear, nose and throat surgery and neurosurgery. When conflict occurs far from the UK base it is essential that the expertise of these specialities is available in the theatre of War and this can only be achieved at short notice by uniformed specialists with adequate military as well as medical experience. In addition the increasingly demanding nature of surgical specialist training has made the traditional Military General Surgeon obsolete. Military surgeons, like their civilian counterparts, cannot now dabble in several fields. Specialist orthopaedic, bowel and urological surgeons will be required in any future conflict.

History also teaches that in all major conflicts this century and probably in the entire history of warfare, the attrition from sickness exceeds that from battle casualties. Physicians are essential and not just general physicians - dermatologists will be required to cope with the likely increase in skin problems associated with occlusive NBC clothing; uro-genital medicine specialists have been needed by every military commander since the invention of rape and pillage.

Any modern Army which employs increasing numbers of females must provide a gynaecological service. This is not just a peace-time luxury. The first medical emergency following the cease fire in the Falklands campaign was an obstetric emergency, the first "no-duff" casualty in exercise Crusader 80 in BAOR was gynaecological. The larger the female component the greater is the need for gynaecological services.

The Defence Medical Services have often become involved in disaster relief operations. This is entirely correct as they are part of our national medical resources and can be suitably trained and equipped to offer $\subseteq$ appropriate help in many natural disaster situations: However, history again teaches that any relief teand which does not include obstetric and paediatric expertis is incomplete. In addition, if it continues to be necessa禺 to provide care for soldiers' families outside the U home base, there remains a need to provide, or to contract for, paediatric and obstetric care.

It is clear from the above that a comprehensie hospital service is as essential as the primary care service, but maintaining a comprehensive hospital service is expensive. It demands adequate resources for training and equipment. If the Armed Forces are to $\triangle$ become "leaner, more mobile and more efficient", $\overline{\overrightarrow{ }}$ (which in itself may cost more rather than less), it is at 3 least possible that the optimum medical support to such forces may involve even more expense. It may be possible to offset some of this expense by closer integration of the UK Defence Hospital Services with the National Health Service and from 1992 it may become possible for the Ministry of Defence to derive $\underset{ه}{\overparen{D}}$ income from their medical assets by contracting to the National Health Service.

In both peace and war, commanders will continue to need advice from trained occupational medicine and $\delta$ public health medicine specialists as a moment's reflection will confirm. It is clear that maintenance of an $\delta$ effective medical service to the Armed Forces demands the continued capacity to provide medical care and advice on a broad front. It is an unpalatable truth that modern medical care is expensive but the financial os penalty must be accepted because the British soldier $N$ deserves the best medical care in both war and peace. N The alternative is unthinkable. 